\title{
Reinforcement of Energy Knowledge in Higher Education of African Countries
}

\author{
A. Sánchez ${ }^{1}$, D. Docampo ${ }^{2}$, A. Cancela ${ }^{* 1}$, R. Maceiras ${ }^{3}$ and V. Alfonsín ${ }^{3}$
}

\begin{abstract}
This paper describes the Project HEEMS (Reinforcement of Higher Education as a tool to foster efficient use of energy applied to the poverty reduction within the marine sector through capacity building and regional integration.). This project is part of the cooperation program Edulink II. Edulink is a Higher Education Cooperation Program of European Union with the ACP Countries (African, Caribbean and Pacific). The principal aim of HEEMS is to improve the know how of knwoledge fields related to the efficient use of energy, and take advantage of small scale use of renewable energies as a tool to the development of marine sector. The countries covered by the project are the African Lusophone Countries (excep Angola), that is: Cape Verde, São Tomé and Principe and Mozambique. Actions proposed are related to Energy Access and Efficiency Higher Studies.

Due the University of Vigo expertise on earninig technologies, the learning contents will availables at the University of Vigo Digital Online Campus which is a part of the Campus del Mar: Knowledge in Depth (International Campus of Excellence), at undergraduate, graduate and professional training levels in the fields of renewable energies. Furthermore, ACP HEEMS countries will use the University of Vigo Infrastructure (online education platforms, WebTV, videoconference) and all the material generated by professors at the universities linked to Campus del Mar, even clone totally or partially that infrastructure with the assitance os european technicians. The project will contribute to the training (presential or remotel) of the local trainers, thus allowing new in-person and online teaching programs at the same time. This is project oriented to the training of trainers project.
\end{abstract}

\section{Introduction}

Energy is essential for life. It is importante for people too, as important as is used as an developmen indicator. Availability of cheap and abundant energy with minimum environmental and ecological hazards associated with its production and use is one of the important factors for desired improvement in the quality of life of the people living especially in developing world.

Energy is an important factor in countries economies. The "standard of living" of a country can be directly related to the "per capita energy consumption". Per capita energy consumption is a measure of the development. The enhanced Energy Development

Chemical Engineering Department, University of Vigo, Spain.

${ }^{2}$ Signal theory and communications Department, University of Vigo, Spain.

${ }^{3}$ Defense University Center, Spain

*Corresponding Author. 
Index (EDI) is a multi-dimensional indicator that tracks energy development country-bycountry, distinguishing between developments at the household level and at the community level. In the former, it focuses on two key dimensions: access to electricity and access to clean cooking facilities. When looking at community level access, it considers modern energy use for public services (e.g. schools, hospitals and clinics, water and sanitation, street lighting) and energy for productive use, which deals with modern energy use as part of economic activity (e.g. agriculture and manufacturing). The EDI can be split by indicator and shown over time, helping a range of decision makers to track progress in important elements of individual countries energy development. (IAE, 2014).

Energy education is a new discipline in both developed and developing countries. But, the contents should be very differente beacuse of energy needs are different too. So, it is in developing countries where should be taken into account that those studies can make some decisions about their energy, environment, and educational policy (Keser et al., 2003).

Education also has a crucial role in the development of countries. Education and training must be provided at all levels, but specially at Higher Education to ensure that energy systems meet the highest standards of reliability and efficiency for the develpment of a given country. Thus, renewable energy education is a relatively new field and previously it formed a minor part of traditional engineering courses. Today, renewable energy education is a common discipline in developed countries. But the same situation is not found in developing caountries where there is a lack of availability of these type os studies, particullary those riented to the technical matters of the renewable energies industry (Müller, 2013).

Many of the graduates of these courses have been successful in changing their career paths and have obtained interesting new jobs in the renewable energy industry or in public service agencies concerned with energy or greenhouse policy.

\section{The HEEMS Project}

The overall objective of the Edulink II Programme is to foster capacity building and regional integration in the field of higher education through institutional networking, and to support higher education of quality, that is efficient and relevant to the needs of the labour market. In accordance with this, the main objective of this project is to foster inter-institutional networking between higher education entities in the ACP countries and EU. The aim is to increase "know how" in the fields related to the efficient use of energy, and take advantage of small scale use of renewable energies applied to the development of marine sector. Within this network, an institutional framework will be formed to enhance the academic performance of HEIs in ACP countries, becoming regional attraction poles with training programmes linked to the labour market and a reference of quality (ACP, 2013). 
On the academic level, the aim is to make available to the HEIs (higher Education Institutions) all the training experience of the University of Vigo, which forms part of the Campus del Mar (Campus of International Excellence), at undergraduate, graduate and professional training levels in the fields of renewable energies. Furthermore, HEIs in ACP countries will profit from the teaching infrastructure of the Digital Campus (online education platforms, WebTV, videoconference) and all the material generated by professors at the universities linked to Campus del Mar. The project will contribute to the training (in-person or not) of the local trainers, thus allowing new in-person and online teaching programmes at the same time.

The action proposed is confined to the target area Energy Access and Efficiency. Within this target area the action will be focused mainly on these thematic fields of Study:

- Innovative solutions to improve access to energy. The action pretends to transfer to the beneficiary countries knowledge already developed by the University of Vigo, related with low cost technologies for accessing to energy.

- $\quad$ Renewable energies. Most of the actions will pursue to reinforce and upgrade the qualification of the academic staff of ACP HEIs in renewable energies, mostly solar energies.

- Policies and strategies and strategies to cleaner, stable electricity (e.g. to householders and businesses). Being this, one of the main problems faced in these countries (cut off of electricity) this action pretends to give capacity building in new energy sources that could complement and substitute the traditional ones and at the same time, be more environmental friendly.

On the other hand the Call encourages linking HEIs to the development plans of the ACP countries. Marine sector is reflected in coastal ACP countries as one of the priorities as it is considered as a productive activity of subsistence. Specific references in Strategic plans to fight against poverty are done to small scale fisheries. Renewable energies come out as potential solutions to specific problems of development of the small scale fisheries sector.

Impact on Development policies will be achieved by making closer academics to real applicability of knowledge and technology to real life. Demonstration Pilot Projects will be developed in order to improve and to add value to academic training programmes, as well as to generate direct impact on development. These will be a tool, a vehicle, for academics to attain real problems and seek useful solutions based on access to efficient and low cost energy. Hence, the Project will address these specific expected results of the Edulink II Programme: - Enhanced contribution to national and regional policies and development plans for cooperation in higher education; - Increased interinstitutional networking between HEIs in the ACP and with EU HEIs, including institutions offering teacher training, degrees and diplomas contributing to regional solutions to teacher shortages; - Upgraded qualifications of academic staff of ACP HEIs; Improved institutional frameworks to pursue academic programmes and academic excellence in ACP HEIs; - Increased mobility of postgraduate students and teaching staff through the provision of joint programmes. 
According to the The Africa-EU Energy Partnership (AEEP), in many African countries, less than $10 \%$ of rural populations have access to electricity. This is a common problem to the three ACP countries involved in the Proposal (Capo Verde, Sao Tomé and Príncipe and Mozambique). This makes difficult the development of any social, economic and productive activity. Access to efficient and low cost energy is considered as one of the keys to improve economic development at large, medium and small scale. Lower accesss to energy is mainly in those populations with low incomes. In the three ACP countries, this is also a common denominator with the description of the main constraints to develop fisheries and aquaculture small scale sector. Following, we reference to main indicators related to energy and marine sector:

- Mozambique: The lack of access to modern sources of energy is mostly driven by the high poverty rate and low household incomes. On average, a typically rural household income is about $\$ 30 /$ month. This income is insufficient to pay for costreflective prices of electricity and fossil fuels. For instance, only 15\% of Mozambican population has access to electricity. Most of these live in the urban areas. In the rural areas (about $80 \%$ of the population), access to electricity is about only $1 \%$. Mozambique's energy policy emphasizes the need for an efficient use of energy resources and the promotion of development of new technologies towards environment friendly and efficient uses of available energy resources. Mozambique has been implementing reforms in the energy sector to promote the development of the enormous energy potential in the country, which includes hydrocarbons, hydropower, coal and renewables such as solar and wind power, biofuels and non-traditional biomass. The Government is committed to stimulate the implementation of a range of power generation projects, at both large and small scales, that will increase the availability of power in general, and contribute to the viable supply of electricity in rural areas, promote income generation activities and employment and self-employment as well as the development of power intensive industries. However, Mozambique has an acute shortage of Engineers specialized in Energy profession. In order to increase specialists who are capable to serve the Energy sector, it is necessary to train people who will have the capacity to solve the energy problems of the local industry and other consumers. Meanwhile, establishing a post-graduate course in Energy means training of people that can undertake and support research into energy matters with focus on energy efficiency and relevant renewable energy sources and technologies for Mozambique. This will contribute to the implementation of Mozambique Science and Technology Strategy 2010 - 2025. In Mozambique HEIs there is a lack of Academic Programmes developed related to energy sciences, which is an important pre-requisite for the real implementation of this policy.

- $\quad$ Cape Verde; Being a country integrated by 10 islands, Cape Verde faces problems not only of access to energy but suffers a lack of stable electricity services that makes that households and families could stand hours without electricity, with the negatives implications that this have for the sustainability of the economy. Cape Verde, has been exploring the renewable energies since three decades. This year has approved a strategic Plan for the development of renewable energies very ambitious that pretends to install $130 \mathrm{MW}$ of potency. HEIs are already developing activities related to the renewal energies, and there are specific institutions related to that. Different initiatives promoted 
within the frame of exchange of experiences have already been developed by other International Institutions with International funding (Spanish Cooperation).

- São Tomé and Principe: In this country electricity is obtained both by hydroelectric plants and from fossil fuels as petroleum or gas. Almost the $60 \%$ of his population live from agriculture and fishing. The mayority of kitchens operate by combusting wood and charcoal (made by rudimentary methods from wood), being this method not environmentally friendly. The country has no specific policies in the development of renewable energies, neither initiatives of relevance. However it does not mean the Govern, HEIs and other stakeholders do not have it in their agenda. This is an opportunity to foster the taking of decisions at different policy makers levels, and HEIs could be part of it. However International Donors are promoting the efficient use of energy in order to lower costs and activities impact. WFP is promoting projects on efficient cooking as well as others. Also the Government has implemented an Extension Service for Fisheries sector in order to increase fisheries sector development through better work security and improve fisheries products added value. All this, as part of the strategy on economic growth and food security.

The final beneficiaries of this project will be the population of the three countries. The increase of knowledge of the teachers and students (future workers) in the countries will imply in the future the development of policies, strategies and practices that will improve the efficiency of the energy used. The participatory approach of this action is guaranteed by the participation of the Institutions in the Consortium, which has a broad experience working and interacting with stakeholders.

Particular added - value elements will be taken into consideration in the designing and implementation of this action, particularly, we have to highlight:

- $\quad$ Through the practical training to the teachers and Students of the target HEIs, knowledge in the development and applications of renewable energy to basic instruments and tool that are important and necessaries for the running of small scale businesses (i.e. processing of fishing products, safety on the see). At this sense, the project could promote public/private partnerships through collaboration between HEIs and businesses.

- Online training for trainers, with state of the art IT tools will enhance capacities and serve as a content generator and network support. Partners will be equipped to facilitate access to it.

- The promotion of the use of renewable energies will contribute to a sustainable, efficient and environmental friendly management of resources.

- Furthermore, gender issues will be attained. Women are main actor in commercialization within small scale fisheries sector. Specific activities will be designed for women within the project and its problematic will be assessed at every stage. An increase in the education level in a country may result in better knowledge and therefore lower AIDS rates. Special attention will be paid to those groups which may be underrepresented because of this condition.

The HEEMS project has an estimated duration of 30 months and, at present, is in an early stage of development. In this first phase, it is the process of identifying the specific 
needs of each country in order to set a consistent educational content with real training needs. These contents, c once identified will be extracted from the specific training programs at the University of Vigo and developed MOOC format to be available from project participant countries.

\section{The University Of Vigo Academic Programs About Renewable Energy}

The Academic Programs related to energy in the University of Vigo are the following:

- Degree in Energy Engineering. This is a new degree on the Spanish university system, which is only taught in three universities in Spain. It comes up as a consequence of the increased demand in renewable energies from public and private sectors in recent years due to changes in the Renewable Energy and Energy Efficiency market. The Skills of the Degree are:

- $\quad$ Acquisition and understanding of basic knowledge on Energy Engineering

- $\quad$ Provide an overview of current energy problems reaching an in-depth training on the relationship between energy and environment.

- $\quad$ Application of the design and optimization tools that are used in power plants

- Acquisition of skills in the field of experimentation: use of experimental techniques used in the field of energy

- Implementation of an appropriate methodology to address the problems of the Energy Engineering Environment

- $\quad$ Training the student to be able to conceive, design, implement and optimize a project on energy issues

- $\quad$ Master of Energy and Sustainability

- The Energy and Sustainability program is an interdisciplinary program with a theoretical and methodological base in technical education, which aims the academic and / or professional trainning students as specialists in sustainable energy industry. The Skills of this Master are:

- $\quad$ Deep knowledge of energy technologies: electrical, thermal and hydrogen

- $\quad$ Knowledge of Electricity Classical Generation: Hydro and Thermal

- Implementation of new renewable energy: feasibility studies and projects (depending on the degree of origin of the student / a)

- Implementation in the company policy of substitution, energy conservation and efficiency

- $\quad$ Implementation of energy audits

- $\quad$ Carrying out environmental audit.

\section{Mooc Format Support}

Massive Open Online Courses were considered as a learning alternative since 2008 when University of Manitoba launched the first mooc course as a "new theory of learning - 'Connectivism' (Siemens, 2013). The rise of social media and networked technologies and the emergence of open and free social tools have influenced our 
communication and interaction in the current digital era. These technologies strongly enable collaboration and global learning experiences can challenge the predominant pedagogical approaches in traditional education discourse and offer the potential for "pedagogical innovation" (Conole, 2008). On the other hand, traditional learning platforms like Moodle extensively used in universities work as a repository more than as a learning tool. Last years, teachers have been complementing learining contents with new learning technologies based activities as webquests, case practices, "knowledge pills" and other "multimedia learning objects". That's why last years a new paradigm has appeared: the personal learning environment.

PLEs have been of interest to many researchers and developers in technology enhanced learning research to examine the technological and pedagogical considerations of such environments in order to conceptualize innovative learning practices supported by the new emerging technologies (Wilson, 2008). Personal learning environments come from the desire to control one's own teaching and learning and in its definition are based on the development of social software applications, Web 2.0". "PLE approach is concerned with changes from the learner's role in the process of learning, personalization of tools and resources, social engagement and self-organization of learning and technological aspects of social software tools and aggregation of multiple resources" (Schafter, 2008). As a meeting point of all these new technologies and way of learning/teaching, the mooc seems to be a useful tool to replace or complement learning platforms. Knowledge in a MOOCs is emergent and MOOC is a catalyst for creating an unpredictable knowledge base for what people is going to learning and which they are going to engage (Downes, 2007). Learning in networks entails some semantic principles including: diversity, autonomy, openness, interactivity or connectedness (Davis, 2008). May be MOOC format allows massive participation leading to the creation of possible educational futures (Wilson, 2008). That's MOOC's are the best learning tools for improve higher education learning in developing countries (Howard, 2014).

\section{Conclusions}

The HEMMS program is a Higher Education Collaboration Program oriented to the Renewable Energies Education Enhancement.

The Project consists on the identification of training o trainer's needs for each country. The University of Vigo in form of specific MOOC provides the technologies for online support to be available once the project has finished.

\section{Aknowledges}

The authors thank the Secretariat of the ACP Higher Education Program EDULINK II.

\section{References}

ACP, African, Caribbean and Pacific Group of States Secretariat, Synopsis of the EDULINK I programme, European Union. Retrieved From: http://www.acpedulink.eu/sites/all/files/documents/docs/EDULINK\%20I\%20Synopsis published.pdf 
Conole, G., de Laat, M., Dillon, T. and Darby, J., 2008. Disruptive technologies, pedagogical innovation: What's new findings from an indepth study of students' use and perception of technology. Computers and Education, 50, 511-524.

Howard Spoelstra, Peter van Rosmalen, \& Peter Sloep, (2014). Toward project-based learning and team formation in open learning environments, J-Jucs, 20, (1), 57-76.

International Energy Agency. (2014, June 28). World Energy Outlook, Methodology for Energy Access Analysis. Retrieved From the International Energy Agency website: http://www.worldenergyoutlook.org/media/weowebsite/energymodel/documentation/EnergyA ccess Methodology 2012 FINAL.pdf.

Keser, Ö. F., Özmen, H., \& Akdeniz, F. (2003). Energy, environment, and education relationship in developing countries' policies: A case study for turkey. Energy Sources, 25(2), 123-133.

Müller, Udo (2013). Technologies and collaborative education strengthen conviviality in rural communities in the Alps and in Senegal. Multicultural Education \& Technology Journal (2), 207-227.

Siemens, G., , What is Connectivism. Retrieved from http://www.elearnspace.org/Articles/connectivism.

Schaffert, S. \& Hilzensauer, W., (2008). On the way towards Personal Learning Environments: Seven crucial aspects. eLearning Papers, 9, 1887-1542.

Wilson, S., (2008). Patterns of personal learning environments. Interactive Learning Environments, 16, (1), $17-34$.

Downes, S., (2007). Learning networks in practice". published in Emerging Technologies for Learning. (David Ley, ed). NRC 49275.

Davis, B., and Sumara, D. (2008). Complexity as a theory of education. Transnational Curriculum Inquiry, 5, (2), 33-44. 